Kucharczuk Magda, Sikorska Hanna, Juraszek Karolina, Wyżgowski Przemysław, Leksowski Krzysztof. Physical activity as one of the elements of a comprehensive obesity treatment. Journal of Education, Health and Sport. 2020;10(3):148-157. eISSN 2391-8306. DOI http://dx.doi.org/10.12775/JEHS.2020.10.03.016

https://apcz.umk.pl/czasopisma/index.php/JEHS/article/view/JEHS.2020.10.03.016

https://zenodo.org/record/3730387

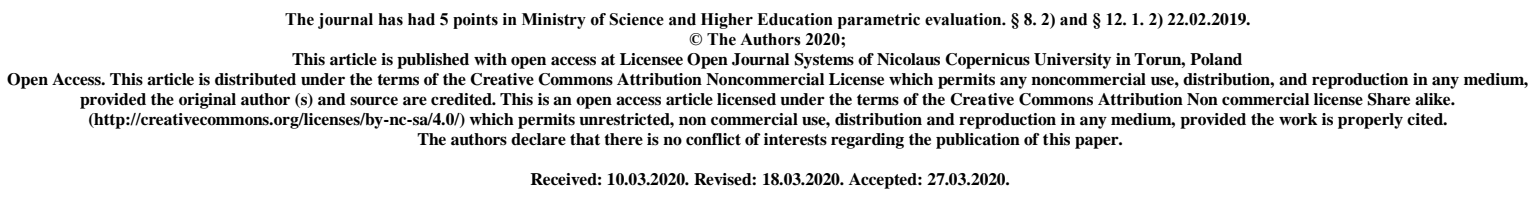

\title{
Physical activity as one of the elements of a comprehensive obesity treatment
}

\author{
Aktywność fizyczna jako jeden z elementów kompleksowego \\ leczenia otyłości
}

\section{Magda Kucharczuk ${ }^{1,2}$, Hanna Sikorska ${ }^{1}$, Karolina Juraszek ${ }^{2,3}$, Przemysław Wyżgowski ${ }^{1}$, Krzysztof Leksowski ${ }^{1}$}

${ }^{1}$ Surgery Unit, 10th Military Research Hospital and Polyclinic, Bydgoszcz, Poland

${ }^{2}$ Department of Physiotherapy, Collegium Medicum in Bydgoszcz, Nicolaus Copernicus University in Toruń, Poland

${ }^{3}$ Eskulap Hospital in Osielsko, Rehabilitation Center, Poland

Address to correspondence:

mgr Magda Kucharczuk

magdakucharczuk1@wp.p1 


\begin{abstract}
Obesity is nowadays a disease of civilization contributing to the increase in mortality worldwide, especially in developing and developed countries. There is a need to take action to normalise the weight of as many people as possible, bearing in mind disadvantageous to the health and the life, effects of exaggerated increasing the amount of the fatty tissue. In this connection, the need to shape patterns of pro-healthy behaviour should be particularly emphasised. The implementation of appropriate physical activity should be one of the basic elements of a comprehensive obesity treatment. Taking into account a wide range of exercises, it is important to choose the right activity for a given person, taking into account their abilities and performance, as well as indications and contraindications to a specific form of training. A key role in the weight reduction process is played by the determination to continue the recommendations made in a long-term and systematic manner. If attempts of the non-invasive treatment turn out to be ineffective, sick persons with the obesity can be qualified for the bariatric surgery. Implementing the physical activity in the period before and post-operative is bringing the sequence of beneficial changes in the body of the patient. It often improves the well-being of patients as well as results in the faster convalescence and lowering the risk of complications. Both the non-invasive and surgical treatment of obesity should be complemented by the introduction of appropriate physical activity.
\end{abstract}

Key words: obesity, physical activity, bariatric surgery

\title{
Introduction
}

The obesity nowadays is a disease associated with the progress of civilization contributing to the rise in the mortality rate worldwide, especially in developing and developed countries [1]. Patients with the obesity have a greater risk of the appearance of cardiovascular diseases, type 2 diabetes, arthritis and even certain types of cancer [1-4]. According to estimates of the World Health Organization 1.6 billion people is suffering because of the excess weight and 400 million are obese. Contemporary civilization development, and with it the change in the way of life, contributes to a drastic reduction in physical activity, what in combination with a high-energy diet, seems to be the fundamental factors causing the occurrence of obesity [5]. In view of the adverse health and life effects of an excessive increase in body fat, there is a need to take measures to normalise body weight in as many people as possible. With reference to the above, it is necessary in the special way to emphasize the need of the forming of patterns of pro-healthy behaviours.

\section{Physical activity}

Physical activity is the basic way to improve physical and mental health. It is a body movement performed by the skeletal muscles, which requires an increase in energy expenditure, which promotes weight reduction. Moreover the physical activity is bringing the number of immeasurable benefits in the form:

- reduction in the fatty tissue, growth of the muscle mass, improvement in the efficiency,

- $\quad$ reducing the risk of many diseases, including diabetes, hypertension, vesicular lithiasis, 
- $\quad$ increase in the sensitivity of tissues to insulin (reduction of insulin resistance),

- $\quad$ improvement of blood lipid profile, improvement of cardiovascular efficiency,

- $\quad$ lowering the rest and effort blood pressure and heart rate

- $\quad$ improving mental well-being and health, reducing anxiety and depression, increasing self-confidence [6].

Taking the above factors into account, it can be concluded that the implementation of appropriate physical activity should be one of the basic elements of a comprehensive obesity treatment. In the process of the dieting applying the balanced diet and the individually selected physical activity are giving good results

The physical activity recommended for the treatment of obesity can be divided into daily and planned activities. By everyday activity we mean any form of movement connected with functioning at home, at work or moving around. Going into a flat up the stairs instead of using the lift, going by bicycle for the shopping, or also an exit from the bus earlier and defeating the rest of distance on foot can be an example. Daily physical activity should be carried out according to the principle: it is better to sit than to lie, to stand than to sit, to walk than to stand [6-8]. Next the planned physical activity should be selected according to FITT criteria:

\section{Frequency}

It is determined through the number of days during the week, which the any form of the physical activity is being led in. It is recommended to undertake training aimed directly at weight reduction 4-5 days a week, while on the remaining days moderate recreational activity. Of course, if possible and necessary you can practice even every day. In determining the frequency of physical activity it may be helpful to use the so-called Physical Activity Pyramid.

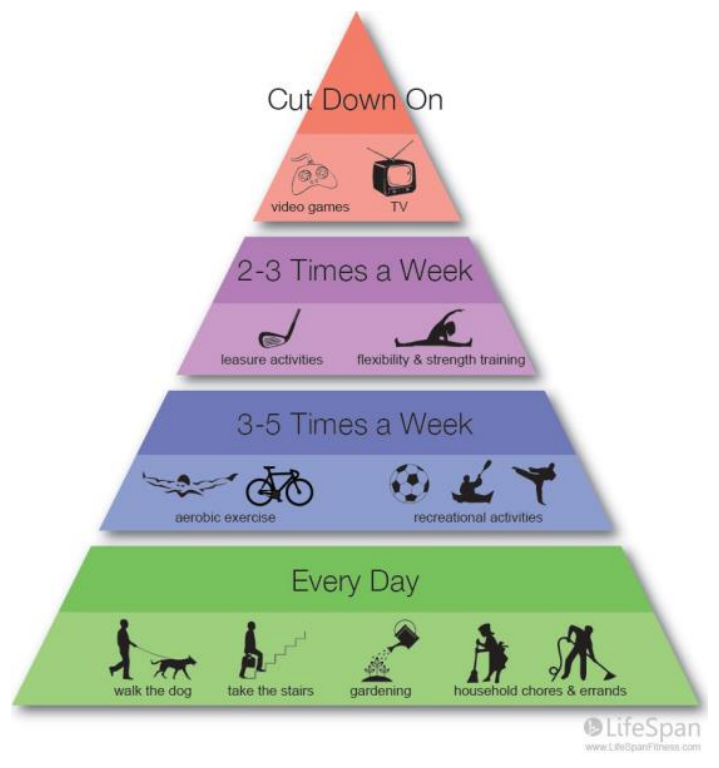

It can be observed that at the base of the pyramid there is the above-mentioned daily activity, further reading from below we can distinguish performance training, resistance and stretching exercises. At the top there are activities that should take up as little time as possible, such as watching TV or playing computer games. Unfortunately, the increasing computerisation, the development of means of transport and the lack of increased need for traffic (e.g. shopping via 
the Internet, driving to work) contribute to a passive lifestyle and thus to a complete reversal of the physical activity pyramid.

\section{Intensity}

This is the degree of intensity that accompanies the effort. The intensity is determined by the heart rate. Physical activity should be carried out at the so-called training heart rate, which is $60-70 \%$ of the maximum heart rate. To calculate the maximum heart rate (HR max) we use a formula: HR $\max =220$ - age. In practice, however, it turns out that patients are reluctant to calculate their training heart rate ranges as well as aren't willing to his inspection. Then it is worth using the "come and talk" rule, which assumes that the possibility of conducting a conversation during the exercises indicates the aerobic nature of the performed effort.

$\underline{\text { Time }}$

Planning the activity we should take three phases into account, in turn: the warm-up, the proper phase and the phase of the calm. The purpose of the warm-up is to prepare the body for exercise by adapting the cardiovascular and respiratory systems and making the muscles and ligament apparatus more flexible. Skipping this phase may result in injuries and traumas during the exercises. In the course of the warm-up a moderate march, stretching exercises, calm general-keep-fit exercises which they should last about 5-15 minutes are applicable. Different forms of the planned activity constitute the specific phase. These can be aerobic, performance exercises or resistance training. If a person is just beginning his or her adventure with exercises, it is important to remember about grading the difficulty level. In the first days we are starting with 10-15 minutes, however in next, as far as possible we are extending the time, ultimately wanting to achieve 60 minutes. The calming phase performed at the end of the training is to continue the exercises from the proper phase, however with lower intensity. It takes about 5-15 minutes. It is advisable to introduce stretching exercises in low positions. The main advantages of the silencing phase are the maintenance of normal blood pressure after exercise and the prevention of cardiac arrhythmia. Apart from that stretching exercises after training help to release the muscles after intensive work.

Type

It is important to remember that exercises do not cause additional strain on the joints of the spine and limbs. People with obesity have a significant load on the joint surfaces, so using exercises that will intensify this can bring the adverse effect in the form of an injury, chronic pain. It can result in immobilizing the sick person for the longer time and discouraging from taking the initiative will cause in consequence further putting on weight. They are examples of exercises which persons with the obesity should avoid: zumba, tabata, jumping on the rope and other forms of physical activity including jumping (e.g. aerobics, trampoline exercises), very intensive training - set to the fast reduction in the fatty tissue (stressing the cardiovascular and skeletal systems), as well as climbing, skiing and running [7-9].

Programming physical activity in people with obesity, two types of training should be considered: aerobic and resistance training. Aerobic training leads to a significant increase in energy expenditure, which creates favourable conditions for reducing excess weight. Additionally, it has a positive effect on the efficiency and effectiveness of the circulatory and 
respiratory systems. These are just some of the advantages of this form of exercise. Examples of aerobic trainings that are recommended for obese people are: aqua aerobic, swimming, walking, Nordic walking, cycling. The aim of resistance training is to improve the efficiency of skeletal muscles and increase bone density. The benefits of strength training are extremely important in people with obesity, who often suffer from muscle weakness, abnormal fat-tomuscle ratio and reduced bone mineral density. Resistance exercises should be performed 2-3 times a week, after about 12-15 repetitions. Examples of resistance exercises:

Starting position

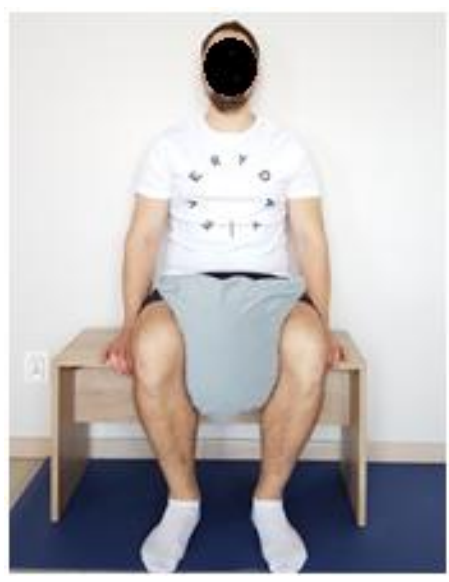

Final position

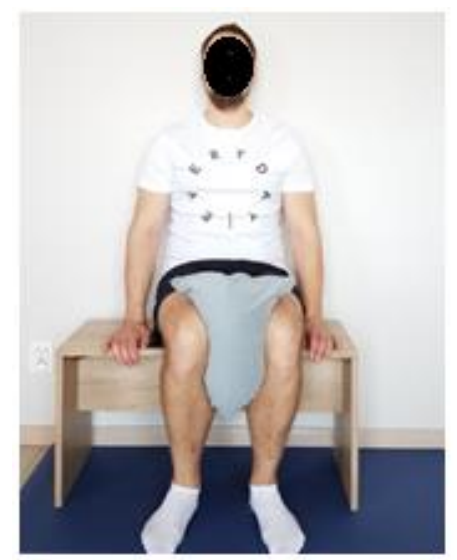

Exercise starting position: sit on the stool without supporting your back! Movement: the practitioner holds a pillow/ball between his legs and tries to squeeze it firmly. The pressure is maintained for about 5 seconds. Muscle groups involved: thigh muscles, abdominal muscles.

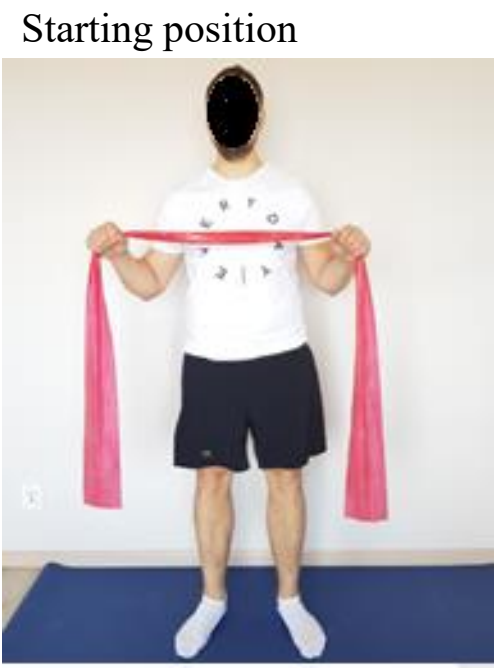

Final position

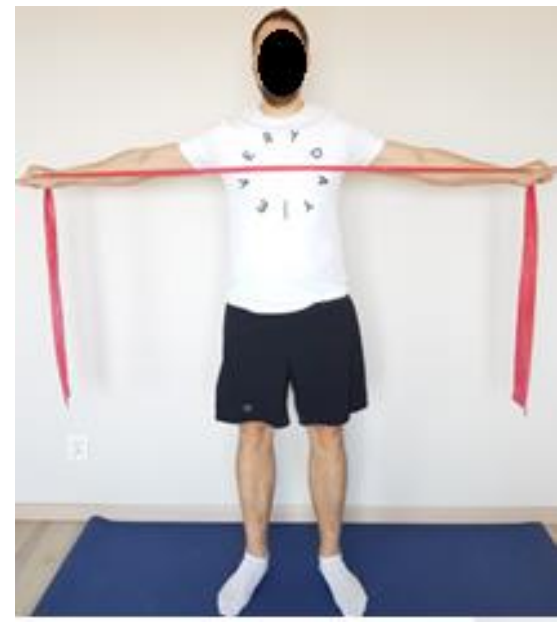

Exercise starting position: standing. Movement: the practitioner stretches the tape outwards and then comes back with the tape tightened all the time. Muscle groups involved: dorsal muscles, shoulder muscles, abdominal muscles. 


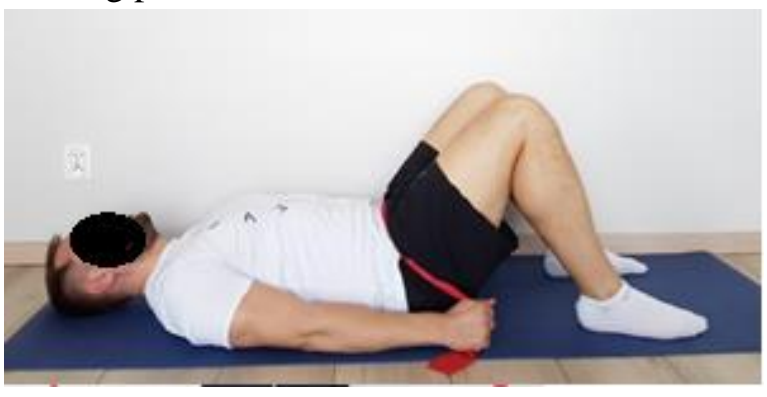

Final position

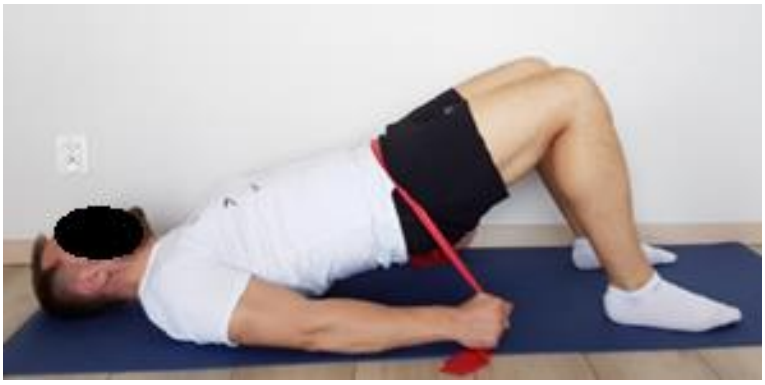

Exercise starting position: lying on your back, your legs bent in your knee joints. the practitioner is holding the tape in both hands, over the belly. Movement: lift your hips up while keeping your hands on the floor. Muscle groups involved: gluteal muscles, dorsal muscles, abdominal muscles, thigh muscles, triceps.

Taking into account a wide range of exercises, it is important to choose the right activity for a person, taking into account the possibilities and indications and contraindications to a particular form of training. The decision to implement physical activity in the patient's life is not the most important. The key role is played by the determination to continue the exercises undertaken in a long-term, systematic way. From here it can be said that it is important that the chosen form of activity is acceptable and, as far as possible, pleasant for the person exercising [9-10].

\section{Examples of forms of mobilisation for physical activity}

\section{Pedometer band}

It is a good idea for people starting their adventure with physical activity to use a pedometer to determine their lifestyle. An approximate range of the number of steps of the average day by the person about the specific level of the physical activity is developing as follows [6]:

\begin{tabular}{|l|c|}
\hline Steps per day & Level of physical activity \\
\hline Less than 3000 & Sedentary lifestyle \\
\hline $3000-6000$ & Low active \\
\hline $6000-8000$ & Somewhat active \\
\hline $8000-10000$ & Satisfactorily active \\
\hline $10000-12000$ & Active \\
\hline More than 12000 & High active \\
\hline
\end{tabular}




\section{Noting of physical activity}

Noting physical activity including the form of training, duration can be another form of mobilization that will motivate to exercise even more effectively. In such a case, a person with obesity can control himself and see how much real effort he has put into his weight loss process. Example table:

\begin{tabular}{|c|c|c|c|c|c|}
\hline Day & Type of activity & Time & Distance & Comments & Steps per day \\
\hline Monday & Resistance exercises & 30 minutes & & & 3300 \\
\hline Tuesday & -------- & & & & 5200 \\
\hline Wednesday & Swimming & 45 minutes & & & 2800 \\
\hline Thursday & --------- & & & Knee pain & 6000 \\
\hline Friday & Resistance exercises & 30 minutes & & & 5600 \\
\hline Saturday & Nordic walking & 60 minutes & $4 \mathrm{~km}$ & High fatigue & 8000 \\
\hline Sunday & Nordic walking & 70 minutes & $4,5 \mathrm{~km}$ & Less fatigue & 9000 \\
\hline
\end{tabular}

\section{Group exercises}

The group form of exercises can motivate to be more systematic. All the more if exercising persons have a common goal, in the form of conducting a healthy lifestyle. It is worth signing up with a colleague, husband/wife for the pool or going for a longer, energetic walk together. An additional motivating factor for physical activity in a group is the wish not to disappoint the training partner.

\section{The importance of physical activity in the context of a bariatric procedure}

Patients with the obesity should be qualified for the bariatric surgery, if attempts at conservative treatment have been made, but they turned out to be ineffective [11]. Nowadays, there are many bariatric surgeries performed around the world, which the most frequently performed are laparoscopic sleeve gastrectomy (LSG) and Roux-Y gastric by-pass (RYGB) [12]. Before the planned bariatric surgery the patient should appropriately prepare. In addition to carrying out the necessary specialist consultations, imaging and laboratory tests, he should achieve the required weight reduction, stop smoking at least 4 weeks before the operation and implement physical activity appropriate to his body weight and physical performance [12-15].

\section{Physical activity before bariatric surgery}

An important element of complex treatment of obesity when selecting surgical treatment is the introduction of physical activity before the operation. "Before" means a few months, not a week. This should be one of the stages of preparation for the procedure, not just waiting time for it. The organism must have time for adopting oneself to the new situation if only exercises caused the desired effect. Planning to begin the physical activity before the surgery the patient can use the training instructions which were put above. In case of any doubts it is worthwhile also getting in touch with the doctor or the physiotherapist. Benefits of implementing physical activity before the bariatric procedure:

1. Helps to reduce the obligatory $7-10 \%$ of body weight in order to qualify for the treatment. In addition, the less fat tissue within the internal organs, the better the visibility of the surgical area, which allows the surgeon to perform the procedure more easily and quickly. 
2. The improvement of the condition and efficiency of the organism, thanks to which the patient will function better after the procedure. One should remember that the first verticalisation takes place about 3 hours after the operation.

3. Change of motor habits. With a pre-surgery training program developed, it will be easier to start activity after the surgery.

4. Improving the functioning of the cardiopulmonary system, reducing insulin resistance of tissues, increasing total energy expenditure and improving the work of mitochondria of skeletal muscles [16-18]

\section{Physical activity after bariatric surgery}

After a laparoscopic bariatric procedure, the patient is verticalised about 3 hours after the surgery. The first verticalisation usually takes place with a physiotherapist or nurse. The patient should learn how to move from a lying to a sitting position in order to avoid excessive strain on the abdominal and spinal muscles. The diagram is as follows: the patient, lying in bed on his back, bends his lower limbs in the knee joints, then rotates to any side and then is moving legs behind the edge of the bed at the same time pushing off with hand from the pillow. When patient already achieves a sitting position with lower limbs apart from the bed, one should wait the moment and calmly proceed to a standing position. Moving on low distance, e.g. by the bed or around the room is a next stage. The recommendations concerning the time of introducing of particular forms of activity after the bariatric surgery ( using the laparoscopic method) are following:

- 1-2 week after the procedure

- leading the economical mode of physical activity limited to walks;

- 3-4 week after the procedure

- leading of next forms of the activity such as nordic walking, bicycle. The pace and distance of march or cycling must be adjusted to the current possibilities of the person which is after the procedure;

- $\quad 1,5$ month after the procedure

- including the moderate resistance training (excluding abdominal muscles) + continuation of recommendations from 3-4 of week with the gradual possibility of increasing the time, the frequency and intensity of performing exercises;

- participation in classes at the swimming pool - swimming, also permitted form of aqua aerobics with limiting of the jumping

- 2 months after the procedure

- resistance training including abdominal muscles + continuation of previous weeks' exercise recommendations.

It is worthwhile also mentioning about respiratory exercises, which are important both in the period before as well as post-operative. Preventing complications on the part of the respiratory system, the maintenance or restoring correct functioning of the respiratory system and the learning of the correct manner of the respiration are a main purpose of respiratory exercises [18-21]. 


\section{Conclusions}

The obesity became one of major health problems of the modern society. A sedentary lifestyle, the automation, the low physical activity and abnormal dietary habits are contributing the progression of the disease. Implementing the appropriate physical activity should be one of basic components of the comprehensive treatment of obesity. Considering the wide range of exercises a due selection of the activity is significant for a given person including her possibility and efficiency as well as indications and contraindications to the specific form of the training. The best results in the process of weight reduction are achieved by using a combination of a balanced diet and individually selected physical activity. These methods are sometimes insufficient. If we are dealing with an advanced form of obesity, the possibility of the bariatric surgery should be considered. Including the physical activity in the period before and post-operative brings a number of beneficial changes in the patient's body. It often affects the well-being of patients as well as results in faster recovery and reduced risk of complications. Both conservative and surgical treatment of obesity should be complemented by the introduction of appropriate physical activity.

\section{References}

1. Freisling H., Viallon V., Lennon H., Bagnardi V., Ricci C. Lifestyle factors and risk of multimorbidity of cancer and cardiometabolic diseases: a multinational cohort study. BMC Med. 2020;18 (1):5

2. Marengoni A., Rizzuto D., Fratiglioni L., Antikainen R. The effect of a 2-year intervention consisting of diet, physical exercise, cognitive training, and monitoring of vascular risk on chronic morbidity - the FINGER randomized controlled trial. J Am Med Dir Assoc. 2018;19(4):355-360

3. Renehan A., Zwahlen M., Egger M. Adiposity and cancer risk: new mechanistic insights from epidemiology. Nat Rev Cancer. 2015;15(8):484-98.

4. Chatterjee S., Khunti K., Davies M. Type 2 diabetes. Lancet. 2017;389(10085): 223951.

5. Szymocha M., Bryła M., Maniecka- Bryła I. Epidemia otyłości w XXI wieku. Zdr Publ 2009;119(2):207-212

6. Osiński W. Nadwaga i otyłość, aktwyność fizyczna w profilaktyce i terapii. PZWL Warszawa 2017

7. Plewa M., Markiewicz A. Aktywność fizyczna w profilaktyce i leczeniu otyłości. Endokrynologia, Otyłość i Zaburzenia Przemiany Materii 2006; 2 (1): 30-37

8. Mcinnis K., Franklin B,. Rippe J. Counseling for Physical Activity in Overweight and Obese Patients, American Family Physician 2003; 67(6)

9. Gołębiewski P., Bryl W., Hoffmann K. Wpływ wybranych technik fizjoterapeutycznych na redukcję masy ciała u osób otyłych. Forum Zaburzeń Metabolicznych 2013;4(1): 37-42

10. Łysak A., Walentukiewicz A. Trening zdrowotny w leczeniu otyłości. Rehabilitacja w Praktyce 2010;1: 26-30

11. Baker MT. The history and evolution of bariatric surgical procedures. Surg. Clin.

North Am. 2001; 91(6):1181-201 
12. Stefura T., Skomarovska O., Wysocki M., Janik M., Krzysztofik M. Challenges associated with bariatric surgery - a multi-center report.. Wideochir Inne Tech Maloinwazyjne 2019;14(4):526-531

13. Haskins I., Amdur R., Vaziri K. The effect of smoking on bariatric surgical outcomes. Surg Endosc 2014; 28: 3074-80.

14. Wong J., Lam D., Abrishami A. Short-term preoperative smoking cessation and postoperative complications: a systematic review and meta-analysis. Can J Anaesth 2012; 59: 268-79.

15. Myers K., Hajek P., Hinds C., McRobbie H. Stopping smoking shortly before surgery and postoperative complications: a systematic review and meta-analysis. Arch Intern Med 2011; 171: 983-9.

16. Coen PM., Carnero EA., Goodpaster BH. Exercise and Bariatric Surgery: An Effective Therapeutic Strategy.. Exerc Sport Sci Rev. 2018; 46(4):262-270.

17. Coen PM., Tanner CJ., Helbling NL. Clinical trial demonstrates exercise following bariatric surgery improves insulin sensitivity. J. Clin. Invest. 2015; 125(1):248-57.

18. Moya M., Hernández A., Manuel Sarabia J. Bariatric surgery, weight loss and the role of physical activity: a systematic review. European Journal of Human Movement. 2014;32:145-160

19. Wouters E., Larsen J., Zijlstra H., Ramshorst B. Physical Activity After Surgery for Severe Obesity: The Role of Exercise Cognitions. Obes Surg 2011; 21:1894-1899

20. Bond D., Thomas JG., Vithiananthan S. Intervention-related increases in preoperative physical activity are maintained 6-months after Bariatric surgery: results from the bari-active trial. Int. J. Obes. (Lond). 2017; 41(3):467-70.

21. Baillot A., Vallée CA., Mampuya WM. Effects of a pre-surgery supervised exercise training 1 year after bariatric surgery: a randomized controlled study. Obes. Surg. 2018; 28(4):955-62. 